\title{
REPAIRING OF RABBIT SKULL DEFECT BY TGF-ß1-INCORPORATED COLLAGEN SPONGES OF DIFFERENT THICKNESS
}

\author{
Hiroki Ueda, Tatsuo Nakamura, Yasuhiko Tabata, and Yasuhiko Shimizu \\ Institute for Frontier Medical Sciences, Kyoto University, Kyoto, Japan
}

\begin{abstract}
We have recently demonstrated that a collagen sponge incorporating TGF- $\beta 1$ was effective in inducing bone repair at the skull defect of rabbits. In this study, the bone repairing of rabbit skulls was tried by TGF- $\beta 1$-incorporated collagen sponges of different thickness to assess the influence of the size of osteoinductive materials on the bone repairing.

The collagen sponge used was prepared by foaming and freeze-drying $1 \%$ aqueous solution of pepsin-processed porcine atelo-collagen, followed by dehydrothermal crosslinking for $6 \mathrm{hr}$ in vacuo. Collagen sponges with different thickness were prepared by changing the volume of collagen solution for freeze-drying and changing the number of sponges piled up. An aqueous solution of TGF- $\beta 1$ or ${ }^{25}$ I-labeled TGF- $\beta 1$ was dropped onto the freeze-dried sponge to prepare collagen sponges incorporating $T G F-\beta 1$ or ${ }^{125} I-T G F-\beta 1$, respectively. Collagen sponges were also radioiodinated with Bolton Hunter Reagent. Following implantation of the collagen sponges incorporating ${ }^{125} I-T G F-\beta 1$ and the ${ }_{125}^{12}$-labeled collagen sponges into the mice subcutis, each radioactivity remaining was measured to compare the time profile of in vivo retention of TGF- $\beta 1$ with that of the sponge. The TGF- $\beta 1$ incorporated collagen sponges of different thickness were implanted into full-thickness defects of rabbit skulls with $6 \mathrm{~mm}$ in diameter. The bone repairing at the defect was evaluated in terms of histological and DEXA examinations 6 weeks later.

The remaining radioactivity of ${ }^{125} I$-labeled collagen sponges and ${ }^{125}$ I-labeled TGF- $\beta 1$ incorporated in collagen sponges decreased with time. The remaining periods of radioactivities of the sponges prolonged with an increase in the sponge thickness, but those of TGF- $\beta 1$ were independent with the sponge thickness. The collagen sponge with $2 \mathrm{~mm}$ thickness was the most effective in increasing the bone mineral density at the bone defect. This finding indicated that the sponge thickness is one of the key factors contributing to successful bone repairing.
\end{abstract}

Biomed Eng Appl Basis Comm, 2003 (February); 15: 1-7.

\section{INTRODUCTION}

Collagen is the most abundant macromolecule in

Received: Nov. 15, 2002; Accepted: Feb. 15, 2003

Correspondence: Tatsuo Nakamura, Assoc. Professor Institute for Frontier Medical Sciences, Kyoto University, 53 Kawara-cho Shogoin, Sakyo-ku, Kyoto 606-8507, Japan

E-mail: nakamura@frontier.kyoto-u.ac.jp the body which functions as the extracellular matrix in various tissues during development and regeneration processes. It is, undoubtedly, one of the most suitable biomaterials for autogeneous tissue repairing because of its biocompatibility and appropriate absorbability. We have demonstrated that the collagen sponge artificially prepared is an effective scaffold matrix to promote the regeneration process of several tissues, for examples, the peripheral nerve, esophagus, trachea, and periodontium[1-4]. However, when the defect to be repaired is large in size, usage of only the collagen sponge of scaffold matix is not enough for tissue re- 
pairing. One possible way for promoted tissue repairing is to combine suitable growth factors and cytokines with the scaffold matrix. For example, transforming growth factor (TGF) B1 is reported to be effective for bone repairing because it activates the proliferation and differentiation of osteoblast precursor cells [5-18]. However, even if a high dose of growth factor was injected in an aqueous solution form, it would be difficult to expect the desired biological effect in vivo because of the short half-life of growth factor in the body. Thus, it is indispensable for the improved in vivo high efficacy to achieve the controlled release of growth factors, which can maximize the expected effects by localizing the factor at the site of action for a prolonged period, while the systemic side-effects can be minimized eventually. It is well recognized that the in vivo activities of growth factors are regulated by the natural release system. Most of growth factors naturally bind to the regulatory molecules present in the extracellular matrix and are released through watersolubilization of the factors bound by enzymatic degradation of the molecules, when required[19-21]. We have recently demonstrated that a collagen sponge incorporating TGF- $\beta 1$ act not only as a tissue scaffold for bone repair but also as a release carrier of TGF- $B 1$ simultaneously. The system was effective in inducing bone repairing at the skull defect of rabbits[22]. However, the size and shape of bone defects to be repaired are different depending on the site applied. Thus, it is necessary for bone tissue engineering to investigate how the size of osteoinductive materials applied to a bone defect affects that of repaired bone tissues. In this study, rabbit skull defects were applied with TGF- $\beta 1$ incorporated collagen sponges of different thickness to assess the effect of sponge size on the bone repairing at the defect.

\section{MATERIALS AND METHODS}

\subsection{Materials}

A solid sample of atelocollagen, (70 wt $\%$ type I collagen and $30 \mathrm{wt} \%$ type III collagen) prepared with pepsin treatment from porcine skin, was supplied by Nippon Meat Packers Inc., Osaka, Japan, and used for sponge preparation. Human recombinant TGF- $\beta 1$ (Lot AV248010) was purchased from R \& D Systems, Minneapolis, MA. Human recombinant TGF-B1 labeled with $\left[{ }^{125} \mathrm{I}\right]-$-Bolton Hunter reagent $\left({ }^{125} \mathrm{I}\right.$-labeled TGF- $B 1,185 \mathrm{kBq} / \mathrm{mL}$ in $0.05 \mathrm{M}$ sodium acetate buffer) and N-succinimidyl-3-(4-hydroxy-3-[25 I] iodophenyl) propionate $\left(\left[{ }^{125} \mathrm{I}\right]\right.$-Bolton-Hunter Reagent (diiodinated)) were obtained from NEN ${ }^{\otimes}$ Life Science Products Inc., Boston, MA.

\subsection{Preparation and Dehydrothermal Crosslinking of Collagen Sponges}

The atelocollagen was dissolved in $\mathrm{HCl}$ aqueous solution at $\mathrm{pH} 3$ to give a final concentration of 1.0 $w t \%$. The collagen solution was whipped on a homogenizer (Nissei AM3, Nihonseiki Kaisha Ltd, Japan) $(8,000 \mathrm{rpm}, 15 \mathrm{~min})$ cooling on ice. The whipped collagen solution was poured into a plastic mold. (7.5 $x 11 \mathrm{~cm}^{2}$ and $2 \mathrm{~mm}$ deep for the preparation of sponges with 0.5 and $1.0 \mathrm{~mm}$ thickness and $6 \mathrm{~mm}$ in diameter and $3 \mathrm{~mm}$ deep for the preparation of the sponges with $3.5 \mathrm{~mm}$ thickness). Collagen sponges of $0.5,1$, and $3.5 \mathrm{~mm}$ thickness were prepared by changing the volume of collagen solution used for freezedrying. Immediately after frozen at $-80{ }^{\circ} \mathrm{C}$, the collagen solution was freeze-dried to obtain a sponge. The freeze-dried collagen sponge obtained was removed form the molds and crosslinked in a vacuum at $140{ }^{\circ} \mathrm{C}$ for $6 \mathrm{hr}$. In this study, the dehydrothermal crosslinking method was chosen because it is toxicologically acceptable and makes homogeneous crosslinking through the sponge, different from several chemical or ultraviolet light induced crosslinking methods, respectively[23-25]. The time length of crosslinking was selected because the best bone repair was achieved at 6 $\mathrm{hr}$ upon using a collagen sponge incorporating TGFB1[22]. The median pore size of the sponge prepared was about $100 \mu \mathrm{m}$. Sponge disks with $6 \mathrm{~mm}$ in diameter were punched out from the obtained sponge sheets with 0.5 and $1 \mathrm{~mm}$ thickness. Sponge samples with 2 , 4 and $6 \mathrm{~mm}$ thickness were prepared by piling up 2, 4 and 6 sponge disks with $1 \mathrm{~mm}$ thickness, respectively. Sponge samples with $7 \mathrm{~mm}$ thickness were prepared by piling up 2 sponge disks with $3.5 \mathrm{~mm}$ thickness.

\subsection{TGF-B1 Incorporation Into Collagen Sponges}

$A$ solution of TGF- $B 1$ or ${ }^{125}$ I-labeled TGF- $\beta 1$ (18.5 kBq.) in phosphate-buffered saline (PBS, $\mathrm{pH} 7.4$ ) (10 $\mu \mathrm{l} / \mathrm{l} \mathrm{mm}$ thickness) was dropped the collagen sponge to evaluate in vivo bone repair and TGF- $\beta 1$ release, respectively. The sponge was then left for $12 \mathrm{hr}$ at $4{ }^{\circ} \mathrm{C}$ to allow the TGF- $\beta 1$ or ${ }^{125}$ I-labeled TGF- $\beta 1$ to incorporate, respectively. Each solution was completely soaked into the collagen sponge because the solution volume was much less than that the theoretically required for the equilibrated swelling of sponge. As a control, TGF- $B 1$-free, empty collagen sponges were prepared by the addition of PBS without TGF-B1.

\subsection{Animal Experiments}

All the animal experiments were performed according to the Guidelines of Animal Experiment of Kyoto University (1985). All the operation procedures were performed under the condition anesthetized with Nembutal (Pentobarbital Sodium $50 \mathrm{mg} / \mathrm{kg}$ ) (Dainippon Pharmaceutical Co., Ltd, Japan). The collagen sponges were sterilized with ethylene oxide gas for the in vivo experiments. 


\subsection{Evaluation of In Vivo Degradation of Col- lagen Sponges}

Collagen sponges were radioiodinated by use of $\left[{ }^{125} \mathrm{I}\right]$-Bolton-Hunter reagent [28]. Briefly, $25 \mu \mathrm{l}$ of $\left.{ }^{125} \mathrm{I}\right]$-Bolton-Hunter reagent benzene solution was dried by bubbling nitrogen gas, and then $700 \mu$ l of PBS were added to prepare the PBS solution of $\left[{ }^{125} \mathrm{I}\right]$ Bolton-Hunter reagent. The resulting PBS solution (10 $\mu \mathrm{l} / 1 \mathrm{~mm}$ thickness) was incorporated into the freezedried collagen sponge (with 1,2 , and $4 \mathrm{~mm}$ thickness, $6 \mathrm{~mm}$ in diameter). The sponge was then left at $25{ }^{\circ} \mathrm{C}$ for $30 \mathrm{~min}$ for radioiodination. The ${ }^{125}$ I-labeled collagen sponges were washed with double-distilled water (DDW) twenty times to remove the non-reacted residual reagent. The ${ }^{125}$ I-labeled collagen sponges prepared were implanted into the back subcutis of 6-week-old female ddY: Std mice (Shimizu Laboratory Animal Supply Co. Ltd, Kyoto, Japan). Each experimental group was composed of 3 mice. At different time intervals, the mice were sacrificed and $200 \mu \mathrm{l}$ of the blood sample was collected by syringe aspiration directly from the heart. The skin of mouse back ( $3 \times 5$ $\mathrm{cm}^{2}$ ) around the implanted site of sponge was removed while the underlying fascia was thoroughly wiped with a filter paper to collect the radioactivity present thereat. The remaining radioactivity of the blood sample, the sponge, the skin, and the filter paper was measured with a gamma counter (Aloka, Auto Well Gamma System ARC-300) to evaluate the in vivo time profile of collagen sponge degradation. The remaining radioactivity in the sponge, the skin, and the filter paper was expressed as the percentage of radioactivity to the sponge initially implanted and solution initially injected.

\subsection{In Vivo TGF-B1 Release Test}

Collagen sponges incorporating ${ }^{125}$ I-labeled TGFB1 were subcutaneously implanted into the back of mice. Each experimental group was composed of 3 mice. The remaining radioactivity at the implanted or injected site and the surrounding tissue was measured at different time intervals to evaluate the time profile of in vivo TGF- $B 1$ release. The remaining radioactivity was expressed as the radioactivity of percentage to the sponge initially implanted and the solution intially injected. The time profile of in vivo retention of TGF-BI was compare with that of the sponge.

\subsection{Assessment of Bone Repairing by TGF-B1 Incorporated Collagen Sponges with Different Thickness}

To evaluate the biological activity of collagen sponges incorporating TGF- $B 1$, their ability to repair the defects of rabbit skulls was assessed(29). Under anesthesia, the head skin and pericranium of Japanese white rabbits weighing 2--2.5 kg (Shimizu Laboratory Animal Supply Co. Ltd, Kyoto, Japan) were cut to ex- pose the skull. Bilateral full-thickness (approximately $2 \mathrm{~mm}$ depth) skull defects with a diameter of $6 \mathrm{~mm}$ were carefully prepared by a microdrill (MINITAR Co., MINIMO POWER PACK C710, Tokyo, Japan). A surgical microscope was used not to injure the underlying dura mater during surgery. The collagen sponges incorporating $0.1 \mu \mathrm{g}$ of TGF- $B 1(10 \mu \mathrm{l} / 1 \mathrm{~mm}$ thickness) with $0.5,1,2,4,6$, and $7 \mathrm{~mm}$ thickness and $6 \mathrm{~mm}$ in diameter were applied to the skull defect. In this study, the TGF- $\beta 1$ dose was selected because complete bone repair was achieved at the dose upon using a gelatin hydrogel incorporating TGF-B1[17]. After sponge application, the pericranium and skin were sutured separately. As controls, the TGF-BI-free, empty collagen sponge and $100 \mu \mathrm{L}$ of PBS with or without $0.1 \mu \mathrm{g}$ of TGF-Bl were used. The experiment was done to 4 defects for each group and each defect was randomly selected from either right or left defect of 4 different rabbits. The skull bone including the defects was taken out 6 weeks postoperatively to evaluate the bone repairing.

The bone repairing was assessed by dual energy $\mathrm{X}$-ray absorptometry (DEXA) and histological examinations. The bone mineral density (BMD) was measured by DEXA at a $6 \times 6 \mathrm{~mm}^{2}$ area within the region of interest with the aid of a bone mineral analyzer (model DCS600, Aloka Co., Tokyo, Japan).

\subsection{Statistical Analysis}

All the data were statistically analyzed using Dunnett's multiple comparison procedure, and statistical significance was accepted at $p<0.05$. Experimental results are expressed as the means \pm standard deviation.

\section{RESULTS}

\subsection{In Vivo Degradation of Collagen Sponges and Release of TGF-B1}

Figure 1 shows the correlation between the thickness of the sponges and radioactivity remaining following subcutaneous implantation of ${ }^{125}$ I-labeled collagen sponges and collagen sponges incorporating ${ }^{125}$ Ilabeled TGF- $\beta 1$. For any type of collagen sponges, the residual radioactivity of ${ }^{125}$-labeled collagen sponges and ${ }^{125}$ I-labeled TGF- $B 1$ gradually decreased with time after implantation into the mouse subcutis. The remaining period of sponges prolonged with an increase in the sponge thickness. However, there was no difference in the remaining radioactivity of ${ }^{125}$ I-TGF- $B 1$ incorporated in the collagen sponges between the sponges, and the in vivo retention of TGF- $\beta 1$ did not depend on the sponge thickness. At 6 weeks postoperatively, all the sponges were thoroughly degraded to disappear from the implanted site. 


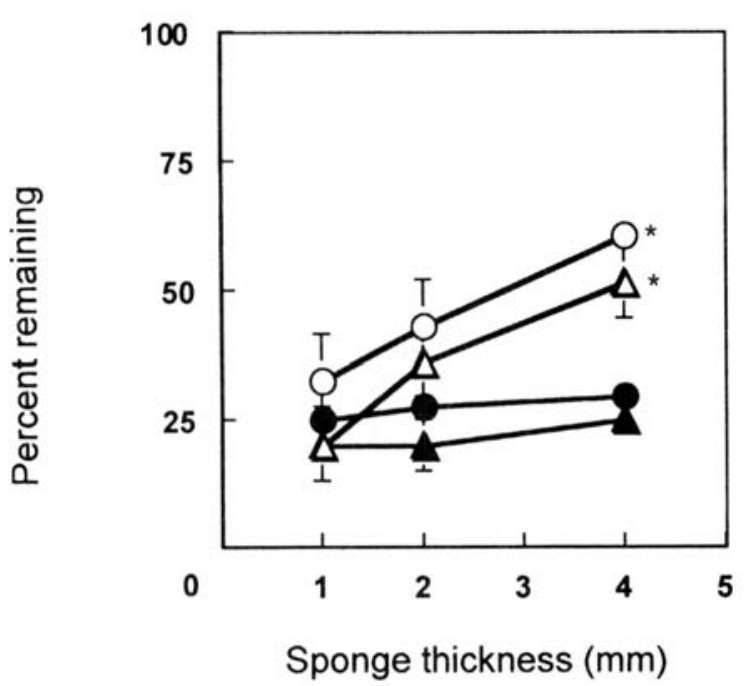

Fig. 1 The radioactivity remaining following the implantation of collagen sponges incorporating ${ }^{125} \mathrm{I}-$ labeled TGF-B1 (solid marks) or the implantation of ${ }^{123}$ I-labeled collagen sponges (open marks) into the mice back for 3 days (circle) and 7 days (triangle). The collagen sponges were dehydrothermally crosslinked for $6 \mathrm{hr}$ with the thickness of 1,2 , and $4 \mathrm{~mm}$. *, $p<0.05$; significant against the radioactivity remaining after implantation of ${ }^{125}$ I-labeled collagen sponges of $1 \mathrm{~mm}$ thickness.

\subsection{Bone Repairing by TGF-B1 Incorporated Col- lagen Sponges with Different Thickness}

Figure 2 shows the osteoinductive nature of TGFB1-incorporated collagen sponges at the skull bone defect. The collagen sponge incorporating TGF- $B 1$ with $2 \mathrm{~mm}$ thickness was the most effective in increasing the bone mineral density (BMD) at the bone defect. The BMD data was supported by the histological examination (Figure 3 ) and soft $X$-ray (Figure 4).

In Figure 3, when TGF- $B 1$ solution and TGF- $B 1$ free empty collagen sponge were used, the skull defect was almost filled by the soft connective tissue, while bone regeneration and repairing were seen only at the edge of the defects along the native dura mater (Figures $3 \mathrm{~B}$ and $\mathrm{C}$ ). On the contrary, for TGF- $\mathrm{Bl}$ incorporated collagen sponge, bone repairing was observed at the skull defect. The bone regeneration of nearly full thickness accompanied with bone marrow was achieved by TGF- $\beta 1$ incorporated collagen sponge with $2 \mathrm{~mm}$ thickness (Figure $3 \mathrm{~F}$ ). The thickness of bone tissue repaired by the thinner or thicker sponges incorporating TGF-Bl was thinner than that of the 2 $\mathrm{mm}$-thick material. Bone regeneration was not initiated from the central portion of defect, but from the defect edge on the side of dura mater. Neither cartilageous tissue nor tissue overgrowth were observed for every

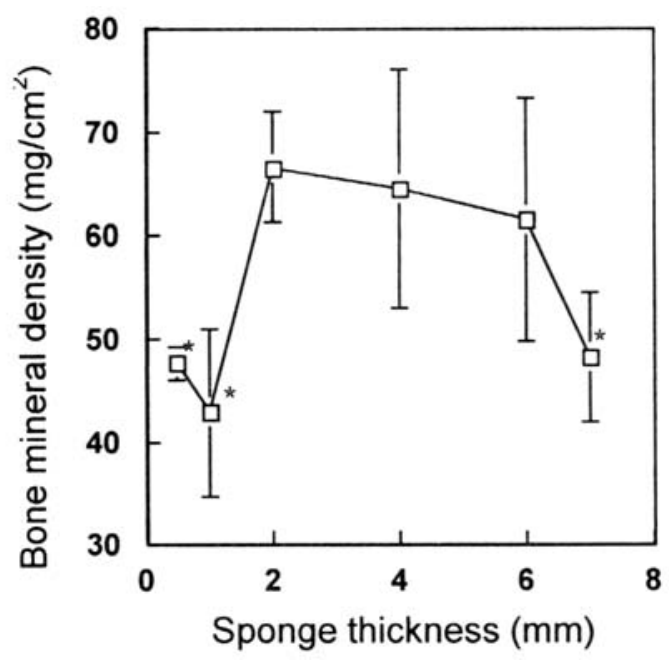

Fig. 2 The bone mineral density of rabbit skull defects 6 weeks after implantation of TGF-B1(0.1 $\mu$ g)incorporated collagen sponge with different thickness. *, $p<0.05$; significant against the $B M D$ value in rabbits treated with collagen sponges incorporating TGF-B1 of $2 \mathrm{~mm}$ thickness.

sample.

It is apparent from Figure 4 that neither TGF- $B 1$ solution nor TGF-free empty collagen sponge induced any morphological change at the bone defects, compared with PBS-treatment (Figures $4 \mathrm{~B}, \mathrm{C}$, and A). The extent of bone repairing by collagen sponges incorporating TGF-B1 depended clearly on the sponge thickness. The optimal thickness of collagen sponges was 2 $\mathrm{mm}$, and application of this thick sponge made the defect most dense radiopaque on the X-ray film showing the calcified bone regeneration (Figure $4 \mathrm{~F}$ ).

\section{DISCUSSION}

We have demonstrated from the TGF- $\beta 1$ release study from collagen sponges of different biodegradabilities that TGF- $B 1$ was released in the body as a result of sponge degradation[22]. In this study, however, the remaining radioactivity of ${ }^{125}$ I-labeled collagen sponges did not correlated with that of ${ }^{125}$ I-TGF-B1 incorporated in collagen sponges after subcutaneous implantation. There are several reasons to be considered. Some of them can be explained by the equilibrium of ${ }^{125}$ I-TGF- $B 1$ between the bound state on the collagen matrix and free state in the tissue fluid. The concentration of ${ }^{125}$ I-TGF- $\beta 1$ in the tissue fluid may be very low considering its circulation in the whole body. The sponge with $4 \mathrm{~mm}$ thickness has 4 times larger volume than that with $1 \mathrm{~mm}$ thickness. As a result, it is possible that the ${ }^{125}$ I-TGF- $B 1$ in the thick sponge is exposed to much larger volume of tissue fluid than that in the thin one, resulting in faster release of ${ }^{125}$ I-TGF- $\beta 1$ 


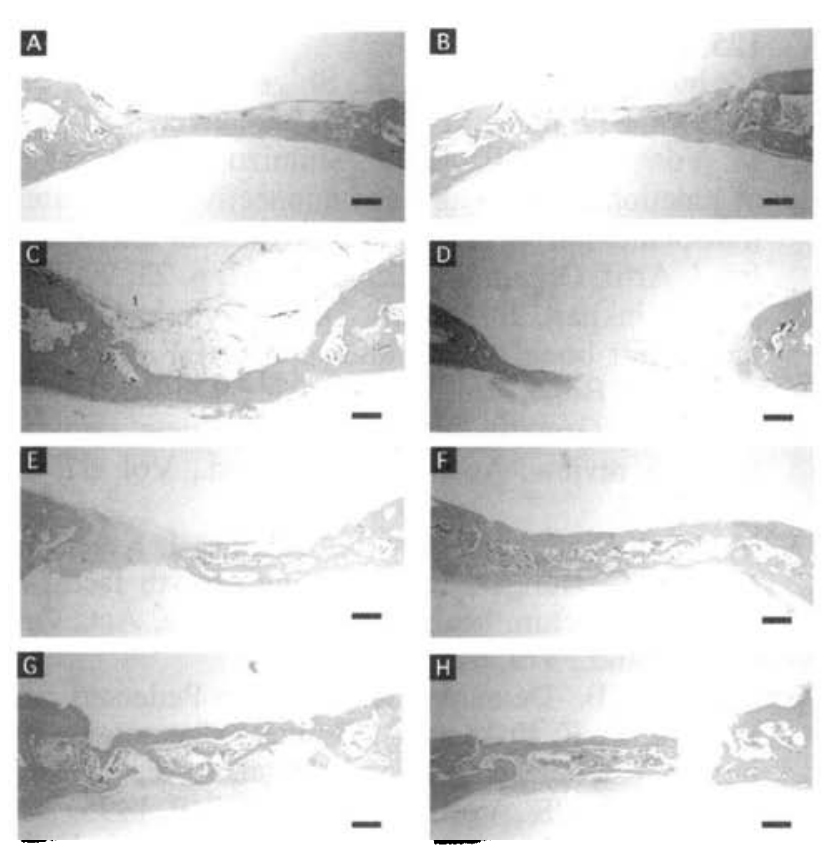

Fig. 3 Histological sections of rabbit skull defects 6 weeks after treatment with PBS (A), $0.1 \mu \mathrm{g}$ of free TGF-B1 (B), a TGF-B1-free collagen sponge with 2

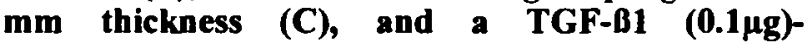
incorporated collagen sponge with different thickness (0.5mm (D), $1 \mathrm{~mm}$ (E), $2 \mathrm{~mm}$ (F), $4 \mathrm{~mm}$ (G), and $6 \mathrm{~mm}(\mathrm{H}))$. The bar length is $1 \mathrm{~mm}$.

from the collagen matrix by the equilibrium detachment. There is the other reason. There exists a small amount of free ${ }^{125}$ I-TGF- $\beta 1$ which is not immobilized to the collagen molecules and existed in the water pathway of collagen matrix. This TGF- $\beta 1$ fraction in the solution form might be pressed out when the sponge was compressed. However, an increase in the number of binding site with the increased surface area of collagen matrix as well as the retention period of sponge matrix made the release of ${ }^{125}$ I-TGF- $\beta 1$ slower. Therefore, by the balance of these factors, there was no difference in the release rate of ${ }^{125}$ I-TGF- $\beta$ ] between the sponges of different thickness.

The present in vivo data suggest that TGF- $\beta 1$ molecules were immobilized into collagen sponges through intermolecular forces acting between the TGF$B 1$ and collagen molecules. TGF-BI was sorbed into collagen sponges faster at $37^{\circ} \mathrm{C}$ than at $4^{\circ} \mathrm{C}$, which indicated that the hydrophobic interaction might contribute to the binding of TGF- $B$ l onto collagen sponges (data not shown). Most of TGF- $\beta 1$ molecules are not released from the collagen sponge in PBS without enzymes where the sponge is not degraded [22]. The forces interacting between the TGF- $B 1$ and collagen molecules are unclear at present and more detailed in vitro researches are underway.

Bone regeneration was initiated from the edge on

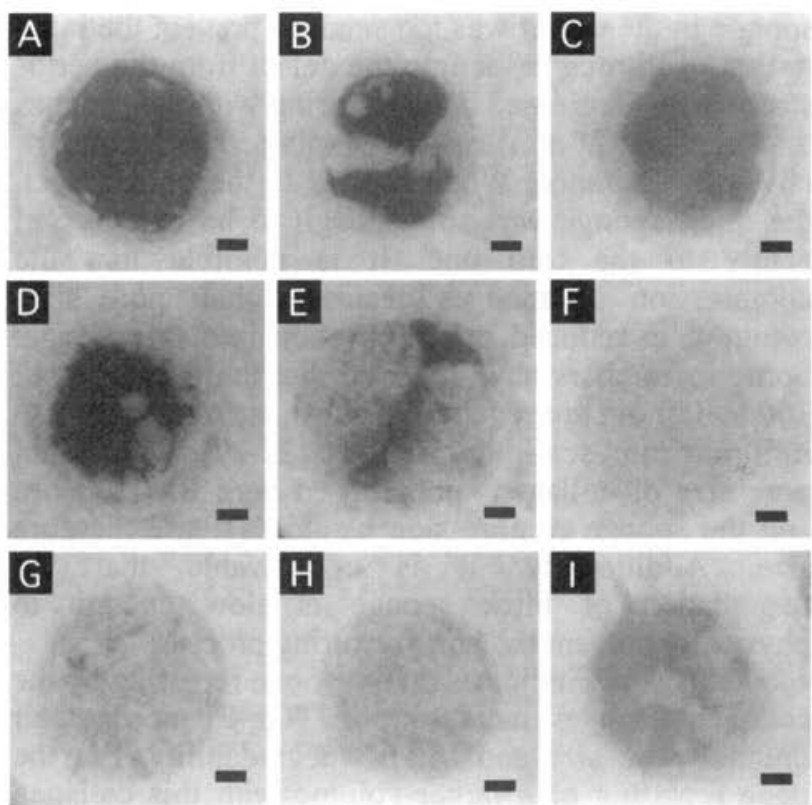

Fig. 4 Soft X-ray photographs of rabbit skull defects 6 weeks after treatment with PBS (A), $0.1 \mu \mathrm{g}$ of free TGF-B1 (B), a TGF-B1-free collagen sponge with 2

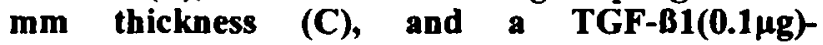
incorporated collagen sponge with different thickness (0.5 mm (D), $1 \mathrm{~mm}(\mathrm{E}), 2 \mathrm{~mm}$ (F), $4 \mathrm{~mm}$ (G), 6 $\mathrm{mm}(\mathrm{H})$, and $7 \mathrm{~mm}(\mathrm{I}))$. The bar length is $1 \mathrm{~mm}$.

the side of dura mater with no chondrogenesis (Figure 3 ). This result suggested that in our system, bone regeneration was performed by the osteogenic cells migrated from the adjacent bone edge or dura and infiltrated into the collagen sponge surface, not by de novo bone differentiation of circulating stem cells migrate deep into the sponges. Blood (oxygen and nutrients) supplied from outer bone and dura could also promote bone regeneration thereat. The upper periosteum could not contribute to the bone regeneration, because it was cut and might be damaged in the implantation procedure. Though the degradation of sponges from outer part might be another reason for the tendency of bone repair site, it is experimentally difficult to detect where the degradation occurs. To reveal the nature of this effect, an experiment with diffusion chambers would be required. The collagen implanted was completely degraded at that time. No cartilaginous tissue was observed. This suggests that bone repair in our system was performed by membranous ossification as same as the development of a skull, that is, surrounding environment of skull would be required for it. No tissue overgrowth was observed in any sample.

The extent of bone repairing by collagen sponges incorporating TGF- $B 1$ depended on the sponge thickness. When the sponge applied was thinner than the depth of bone defect, $2 \mathrm{~mm}$, the bone repair was insufficient. This would be because the occupied volume of 
sponge in the defect was too small to prevent the infiltration of fibrous tissue into the defect from the periosteum side. Decreased bone repairing with the sponges thicker than $2 \mathrm{~mm}$ can be explained in terms of physical hindrance. When applied to the bone defect, the thick sponge was soft enough to be compressed nearly to the thin one. It is possible that the compression of sponges decreases their pore size, resulting in reduced cell infiltration into the sponge. Some researchers have reported that the pore sizes of 100 to $350 \mu \mathrm{m}$ are required to allow osteogenic cells to infiltrate into scaffold materials [26-27]. The initial pore size of collagen sponge used here was $100 \mu \mathrm{m}$ and the sponge compression would decrease the pore size. Additionally, it is conceivable that the degradation of thick sponge is slow enough to physically prevent the bone repairing process.

This study indicates that the bone repairing by the collagen sponges incorporating TGF- $B 1$ needs their optimal pore size and in vivo degradability. For the bone repairing of a larger volume with this collagen system, use of high dose of TGF- $\beta 1$ and large and mechanically reinforced collagen sponges should be prepared.

\section{CONCLUSIONS}

The collagen sponge incorporating TGF- $B 1$ released TGF- $B 1$ and induced bone repairing at the skull defect of rabbits although the extent depended on the sponge thickness. The sponge with the thickness similar to that of skull bone exhibited the highest ability for bone repairing. This finding indicated that the sponge thickness was one of the key factors contributing to successful bone repairing.

\section{REFERENCES}

1. K. Matsumoto, K. Ohnishi, T. Sekine, H. Ueda, T. Kiyotani, T. Nakamura, K. Endou, Y. Shimizu, Use of a newly developed artificial nerve conduit to assist peripheral nerve regeneration across a long distance gap in dogs, Brain Res., Vol. 868, No. 2, p. $315,2000$.

2. Y. Yamamoto, T. Nakamura, Y. Shimizu, K. Matsumoto, Y. Takimoto, T. Kiyotani, T. Sekine, H. Ueda, Y. Liu, N. Tamura, Intrathoracic esophageal replacement in the dog with the use of an artificial esophagus composed of a collagen sponge with double-layered silicone tube, J. Thorac. Cardiovasc. Sur., Vol. 118, p. 276, 1999.

3. T. Sekine, T. Nakamura, K. Matsumoto, Y. Liu, H. Ueda, N. Tamura, Y. Shimizu, Cardinal reconstruction with a $Y$-shaped collagen-conjugated prosthesis, J. Thorac. Cardiovasc. Sur., Vol. 48, No. 3, p.
$125,2000$.

4. M. Inoue, T. Nakamura, K. Shigeno, H. Ueda, N. Tamura, S. Fukuda, Y. Liu, T. Nakahara, T. Toba, M. Yoshitani, T. lizuka, Y. Shimizu, Regeneration of junctional epithelium and connective tissue after transplantation of detergent processed allo-teeth, Int. J. Artif. Organs., Vol. 23, No. 12, p. 23, 2000.

5. T. A. Linkhart, S. Mohan, D. J. Baylink, Growth factors for bone growth and repair: IGF, TGF-B1, and BMP, Bone, Vol. 19, Supplement, p. 1S, 1996.

6. M. Lind, Growth factors: possible new clinical tools. A review, Acta Orthop. Scand., Vol. 67, p. 407, 1993.

7. M. Lind, B. Schumacker, K. Søballe, J. Keler, F. Melsen, $C$. Bunger, Transforming growth factor- $\beta$ enhances fracture healing in rabbit tibiae, Acta Orthop. Scand., Vol. 64, p. 553, 1993.

8. M. Lind, B. Deleuran, K. Thestrup-Pedersen, K. Soballe, E. F. Eriksen, C. Bunger, Chemotaxis of human osteoblasts. Effects of osteotropic growth factors, APMIS., Vol. 103, No. 2, p. 140, 1995.

9. M. Lind, S. Overgaard, B. Ongpipattanakul, T. Nguyen, C. Bunger, K. Soballe, Transforming growth factor- $\beta 1$ stimulates bone ongrowth to weight-loaded tricalcium phosphate coated implants: an experimental study in dogs, J. Bone Joint Surg. Br., Vol. 78, No. 3, p. 377, 1996.

10.M. Lind, S. Overgaard, K. Soballe, T. Nguyen, B. Ongpipattanakul, C. Bunger, Transforming growth factor- $\beta 1$ enhances bone healing to unloaded tricalcium phosphate coated implants: an experimental study in dogs, J. Orthop. Res., Vol. 14, No. 3, p. $343,1996$.

11.M. Lind, S. Overgaard, T. Nguyen, B. Ongpipattanakul, C. Bunger, K. Soballe, Transforming growth factor- $B 1$ stimulates bone ongrowth. Hydroxyapatite-coated implants studied in dogs, Acta Orthop. Scand., Vol. 67, No. 6, p. 611, 1996.

12.T. A. Linkhalt, S. Mohan, D. J. Baylink, Growth factors for bone growth and repair: IGF, TGFB and BMP, Bone., Vol. 19, Supplement 1, p. 1S, 1996.

13.S. N. Khan, M. P. Bostrom, J. M. Lane, Bone growth factors, Orthop. Clin. North Am., Vol. 31, No. 3, p. 375, 2000.

14.L. Hong, S. Miyamoto, N. Hashimoto, Y. Tabata, Synergistic effect of gelatin microspheres incorporating TGF- $B 1$ and a physical barrier for fibrous tissue infiltration on skull bone formation, J. Biomater. Sci. Polym. Ed., Vol. 11, No. 12, p. 1357, 2000.

15. Y. Tabata, L. Hong, S. Miyamoto, M. Miyao, N. Hashimoto, Y. Ikada, Bone formation at a rabbit skull defect by autologous bone marrow cells combined with gelatin microspheres containing TGFbeta1, J. Biomater. Sci. Polym. Ed., Vol. 11, No. 8, p. 891, 2000.

16. L. Hong, Y. Tabata, S. Miyamoto, K. Yamada, K. Aoyama, M. Tamura, N. Hashimoto, Y. Ikada, Pro- 
mote bone healing at a rabbit skull gap between autologous bone fragment and the surrounding intact bone with biodegradable microspheres containing transforming growth factor- $B 1$, Tissue Eng., Vol. 6, No. 4, p. 331, 2000.

17. L. Hong, Y. Tabata, S. Miyamoto, M. Yamamoto, K. Yamada, N. Hashimoto, Y. Ikada, Bone regeneration at rabbit skull defects treated with transforming growth factor-Bl incorporated into hydrogels with different levels of biodegradability, $\mathrm{J}$. Neurosurg., Vol. 92, p. 315, 2000.

18. Y. Yamamoto, Y. Tabata, L. Hong, S. Miyamoto, N. Hashimoto, $Y$. Ikada, Bone regeneration by transforming growth factor betal released from a biodegradable hydrogel, J. Control. Release., Vol. 14, No. 64(1-3), p. 133, 2000.

19.J. Taipale, J. Keski-Oja, Growth factors in the extracellular matrix, FASEB J., Vol. 11, p. 51, 1997.

20.N.M. Barcellos-Hoff, Latency and activation in the control of TGF-beta, J. Mammary Gland Biol. Neoplasia, Vol. 1, No. 4, p. 353, 1996.

21.J.A. Martin, J.A. Buckwalter, The role of chondrocyte-matrix interactions in maintaining and repairing articular cartilage, Biorheology, Vol. 37 , No. 1-2, p. 129, 2000.

22. H. Ueda, L. Hong, M. Yamamoto, K. Shigeno, $M$. Inoue, T. Toba, M. Yoshitani, T. Nakamura, Y. Tabata, Y. Shimizu, Use of collagen sponge incorporating transforming growth factor- $B 1$ to promote bone repair in skull defects in rabbits, Biomaterials, Vol. 23, p. 1003, 2002.
23.X. H. Ma, Y. Noishiki, Y. Yamane, Y. Iwai, D. Marato, A. Matsumoto, Thermal cross-linkage for biologically degradable materials: preliminary report, ASAIO J., Vol. 42, p. M866, 1996.

24.K. S. Weadock, E. J. Miller, L. D. Bellincampi, J. P. Zawadsky, M. G. Dunn MG, Physical crosslinkaging of collagen fibers: comparison of ultraviolet irradiation and dehydrothermal treatment, J. Biomed. Mater. Res., Vol. 29, p. 1373, 1995.

25. K. S. Weadock, E. J. Miller, E. L. Keuffel, M. G. Dunn, Effect of physical crosslinking methods on collagen-fiber durability in proteolytic solutions, J. Biomed. Mater. Res., Vol. 32, p. 221, 1996.

26. B. P. Robinson, J. O. Hollinger, E. H. Szachowicz, J. Brekke, Carvarial bone repair with porous D,Lpolylactide, Otolaryngol Head Neck Surg., Vol. 112, p. 707, 1995.

27. J. J. Klawitter, J. G. Bagwell, A. M. Weinstein, B. W. Sauer, An evaluation of bone growth into porous high density polyethylene, J. Biomed. Mater. Res., Vol. 10, No. 2, p. 311, 1976.

28. A. E. Bolton, W. M. Hunter, The labeling of proteins to high specific radioactivities by conjugation to a 125I-containing acylating agent, Biochem. J., Vol. 133, p. 529, 1973.

29.K. Yamada, Y. Tabata, K. Yamamoto, S. Miyamoto, I. Nagata, H. Kikuchi, Y. Ikada, Potential efficacy of basic fibroblast growth factor incorporated in biodegradable hydrogels for skull bone regeneration, J. Neurosurg., Vol. 86, p. 871, 1997. 